EGU2020-18982

https://doi.org/10.5194/egusphere-egu2020-18982

EGU General Assembly 2020

(c) Author(s) 2021. This work is distributed under

the Creative Commons Attribution 4.0 License.

\title{
Pore Scale Analysis of Suitability for Geological Carbon Storage, Implications for the UK Geoenergy Observatories Project
}

\author{
Ryan L Payton ${ }^{1}$, Mark Fellgett ${ }^{2}$, Andrew Kingdon ${ }^{2}$, Brett Clark ${ }^{3}$, and Saswata Hier-Majumder ${ }^{1}$ \\ ${ }^{1}$ Royal Holloway University of London, Department of Earth Sciences, United Kingdom (ryan.payton.2015@live.rhul.ac.uk) \\ ${ }^{2}$ British Geological Survey, Nottingham, United Kingdom \\ ${ }^{3}$ Imaging and Analysis Centre, Natural History Museum, London, United Kingdom
}

Geological carbon storage (GCS) has been identified as a crucial process in tackling rising anthropogenic $\mathrm{CO}_{2}$ emissions. We examine 4 sandstone cores from the Scottish Middle Coal Measures Formation at the UK Geoenergy Observatories (UKGEOS) site in Glasgow using X-ray micro computed tomographic images to assess the carbon storage capacity. Each 3D microtomographic image was processed by binary segmentation to extract the macroporosity from the greyscale images, pore network analysis to establish the effective porosity, and permeability simulation using a finite volume solver. We compare this location to 7 samples from the Wilmslow Sandstone Formation in Sellafield as a precursor analysis of the laterally equivalent Sherwood Sandstone at the under construction Cheshire UKGEOS site. We find a significant difference in porosity and permeability between the two sites with Sellafield samples showing a porosity range of $9.73-25.31 \%$ whilst Glasgow samples display a range of $0.38-1.65 \%$. The Sellafield samples also show a significant proportion of connected porosity ranging between 8.85 and $25.26 \%$, whilst no connected porosity was found in the Glasgow samples. This is deemed due to the presence of a ubiquitous cement phase occupying up to $26.28 \%$ of the sample volume, significantly reducing the viability for fluid injection and therefore GCS at the Glasgow site. Carbon storage is dependent on the availability of pore space for mineralisation and the pore connectivity which allows for fluid flow of $\mathrm{CO}_{2}$. Our measured values of porosity and permeability also indicate that the Sellafield site and sandstones similar to the samples from this site will be highly effective as CCS target formations. 